\title{
Pierre Grondin, Guiding Spirit of the Montreal-Madrid Agreement
}

On January 17, 2006, Dr Pierre Grondin, founder of the Department of Surgery of the Montreal Heart Institute, Canada, and its director from 1963 to 1979, died at the age of 80 . After leaving the Institute, he directed the Cardiac Surgery Service of St. Francis Hospital in Miami, United States, for over 10 years. In the early 90's, he returned to Canada to set up a cardiac surgery program in l'Hotel Dieu in Québec.

He was a pioneer in heart transplantation in Canada. I met him in 1969, when he visited Seville, where he gave a lecture, offered a surgical demonstration (a Vineberg procedure) and, above all, learned with amazement that open heart surgery was being performed at Hospital de las Cinco Llagas, a 16th century building that now houses the Parliament of Andalusia. A few months later, he wrote to suggest that our group travel to Montreal to learn the coronary artery surgical techniques that they had begun to carry out there. When, on our return-in 1970 - the first coronary artery bypass procedures to be performed in Spain were successful, he contacted the Provincial Council of Seville with an unusual proposal: that an agreement be established between our respective provincial governments. He offered to train medical, auxiliary, technical and even administrative personnel in Montreal and to provide all the necessary equipment for a modern cardiac surgery service, which would be installed and started up by Canadian personnel. All this, for nothing in return, funded by the Government of Québec which, in those days, was struggling to differentiate its international presence from that of Canada. Instead of immediately accepting that generous gift, the Council sent its secretary to visit the Institute and the authorities involved, and to report on them. Although his report was totally favorable, the agreement was never signed; however, the exchange of medical personnel did take place.
In 1972, Pierre Grondin made the same offer to the Provincial Council of Madrid and this time, its president - the prestigious surgeon, Carlos González Bueno-did not hesitate and, that same week, he ordered his vice president-Leopoldo Matas - to travel to Québec and to Ottawa, and not to return until the agreement was signed. It was designed for 5 years, but once the initial objectives (performance of 500 open heart procedures a year) were fulfilled, the agreement was broadened, first to other medical and surgical specialties, to other Canadian hospitals and to physicians from all over Spain, and subsequently to fields other than medicine (agriculture, aquaculture, forest fires, etc). Even in aspects so unrelated to his profession, Grondin continued to be the person behind all the agreements and connections that were requested of him from Spain. His enthusiasm for Spain, its history, its monuments, its language and its people knew no limits. His home in Laval sur le Lac was a genuine consulate, where he, who spoke Spanish fluently, and Marjo-his wife-who spoke it perfectly, solved all the problems of the more than 300 Spaniards who-between fellows and their families-arrived in Canada.

Hospitals in Catalonia, Andalusia, Castile, Cantabria, the Basque Country and, of course, Madrid benefited from these exchanges and, today, the medical and surgical specialists trained in Canada hold positions of the highest prestige in these centers. In particular, the fields of cardiology and cardiac surgery of all of Spain have reason to be especially grateful to Pierre Grondin. 